\title{
Tethering mobile aquatic organisms to measure predation: A renewed call for caution
}

\author{
Ronald Baker $^{\mathrm{a}, *}$, Nathan Waltham ${ }^{\mathrm{b}, \mathrm{c}}$ \\ ${ }^{a}$ Department of Marine Sciences, University of South Alabama, Dauphin Island Sea Lab, 101 Bienville Blvd. Dauphin Island, AL 36528, USA \\ ${ }^{\mathrm{b}}$ TropWATER, Centre for Tropical Water and Aquatic Ecosystem Research, James Cook University, Townsville, Queensland, Australia \\ ${ }^{\mathrm{c}}$ Marine Data Technology Hub, College of Science and Engineering, James Cook University, Townsville, Queensland, Australia
}

\section{A R T I C L E I N F O}

\section{Keywords:}

Experimental artefacts

Sample independence

Mortality

Survival

Predation

Underwater video

\begin{abstract}
A B S T R A C T
Tethering experiments are one of the few approaches available to ecologists to assess predation rates in aquatic environments, and they have provided important insights into the processes driving observed patterns in aquatic communities. The potential for experimental artefacts to arise when tethering mobile prey has been well recognised and was vigorously discussed in the literature around 20 years ago. However, we reviewed 128 published studies that tethered fish and mobile crustaceans and found a growing number since that time that we believe do not adequately consider these potential issues. The majority of studies recognise that tethering mobile prey can only provide a relative rather than absolute estimate of predation rates, yet $16 \%$ present and interpret their results as if they reflect absolute natural predation rates. Two thirds of published studies at least acknowledge other potential artefacts, less than half test for them, while one third seemingly give no consideration to potential artefacts or biases of the method. Our review also revealed the potential for a lack of independence between individual replicates. More than two thirds of studies deployed replicate tethered prey a minimum of no $>5 \mathrm{~m}$ apart, with more than one quarter deploying them no $>1 \mathrm{~m}$ apart. Eighty-five percent of studies considered missing prey to represent predation. We deployed 104 tethered fish prey in field trials and monitored them using remote underwater video to determine the causes of prey loss. These trials reinforced the simple but important point that prey missing from tether lines at the end of an experiment can be missing for a variety of reasons other than reflecting predation. They also highlight the potential for underwater video, where it is practical to use, to overcome many of the issues confronting field tethering experiments. Carefully designed tethering studies will continue to be an important tool for ecologists studying patterns of predation in aquatic systems. However, our findings suggest a re-emerging need for researchers to recognise and test for potential biases and artefacts inherent with the technique.
\end{abstract}

\section{Introduction}

Tethering experiments are widely used to assess patterns of predation in aquatic systems where extensive direct observations of predation processes are not possible (Aronson and Heck, 1995). The procedure involves restraining prey in a particular location for a period of time to measure their rate of removal as an indication of natural predation pressure. Data on the patterns of tethered prey loss are then used to infer patterns in predation pressure among aquatic habitats (e.g. Smith et al., 2011; Bromilow and Lipcius, 2017), through time (e.g. Minello, 1993), across prey sizes (e.g. Riley and Griffin, 2017), or among prey types (e.g. Aronson, 1988). Such studies have provided insights into how predation may structure communities in a variety of aquatic ecosystems (Aronson and Heck, 1995; Smith et al., 2011; Riley and Griffin,
2017).

That tethered prey are likely more vulnerable to predation than untethered free-swimming prey is widely recognised, and most authors acknowledge this by interpreting their results as estimates of relative predation pressure rather than absolute predation rates (Aronson, 1989). Restraining mobile prey on a tether may alter its behaviour and thereby alter the probability of detection or consumption by predators relative to naturally behaving un-tethered prey (Aronson, 1989; Zimmer-Faust et al., 1994; Halpin, 2000; Pursche et al., 2009). The usual assumption in field tethering studies, as articulated by Peterson and Black (1994), is that if experimental methods are applied identically across all treatments, then any artefacts of this intervention will also be equal among treatments, and thus not bias the observed patterns. However, if the effect of tethering on the probability of loss from

\footnotetext{
* Corresponding author.

E-mail address: rbaker@disl.org (R. Baker).
} 
the tether interacts with the treatment of interest, then the measured patterns of prey loss may be a poor representation of the underlying natural patterns of predation we seek to understand (Peterson and Black, 1994).

The potential artefacts of tethering experiments have received considerable attention through both experimental studies (e.g. Barshaw and Able, 1990; Zimmer-Faust et al., 1994; Curran and Able, 1998; Haywood et al., 2003; Adams et al., 2004; Mills et al., 2008) and debate in the literature (Peterson and Black, 1994; Aronson and Heck, 1995; Kneib and Scheele, 2000; Aronson et al., 2001). Several studies have demonstrated significant interactions that confound observed patterns (e.g. Barshaw and Able, 1990; Haywood et al., 2003; Adams et al., 2004; Mills et al., 2008). For example, Barshaw and Able (1990) demonstrated that tethering differentially impacted the ability of juvenile American lobsters to burrow and avoid predation in different substrates. In such cases the effect of tethering on prey vulnerability varies among treatments, therefore confounding results based on patterns of tethered prey loss (Peterson and Black, 1994). Of course, the potential for artefacts does not mean they will always arise to confound results, and a few authors have used field observations or conducted careful tests to avoid (Smith et al., 2011) or confirm a lack of interaction (Yeager and Hovel, 2017) between treatment and the vulnerability of tethered prey.

All experimental interventions have the potential to introduce biases or artefacts that confound results (Peterson and Black, 1994; Aronson et al., 2001). Despite the possible problems, tethering remains one of the few approaches to examining patterns in predation in aquatic environments, and may be particularly powerful when combined with a variety of approaches to gain insights into community structure and function (e.g. Linehan et al., 2001; Manderson et al., 2006; Mills et al., 2008; Riley and Griffin, 2017). A point of consensus in the debate is the need to continue to evaluate the validity of tethering techniques to ensure that our understanding of predation in aquatic systems is based on valid and robust data (Kneib and Scheele, 2000; Aronson et al., 2001; Adams et al., 2004; Smith et al., 2011). In light of the increasing application of tethering methods, particularly for mobile fishes and crustaceans, the objectives of the present study were: 1) to determine the extent to which published studies recognise and address potential confounding factors when conducting tethering experiments with mobile prey (fishes and nektonic crustaceans); and 2) to assess the common assumption that prey loss from tether lines represents predation, using remote underwater video to identify the causes of prey loss during field tethering deployments.

\section{Methods}

\subsection{Literature review}

We reviewed the literature on experiments tethering nektonic prey to determine the extent to which the potential biases of this approach have been considered and addressed. We searched the Web of Science and Google Scholar (last accessed 11 Feb 2019) with the terms "tether" " and "fish" or "shrimp" or "prawn" or "crab" or "crayfish" or "lobster", and considered all studies reporting primary data from field tethering experiments in any aquatic environment. This search provided a total of 128 studies spanning freshwater, estuarine and marine environments, tethering a range of fish and mobile crustaceans. Our analysis focussed on the potential biases of tethering mobile nekton, and how these issues were addressed. In particular we determined: 1) if missing prey were considered to represent predation events, 2) if the results were interpreted as representing absolute or some relative measure of predation rate; 3 ) if potential biases were discussed and/or tested through field or laboratory experiments, and 4) if some or all of the events were observed or captured on film to identify causes of prey loss from tethers and other potential artefacts. There are also potential issues of non-independence when replicate tethered mobile prey are deployed in close proximity to each other. Therefore, we examined the minimum distance reported between tethers if this information was provided.

\subsection{Field tethering trials}

To identify the causes of prey loss from tethers, and to test the use of underwater video as a method to improve tethering experiments, we deployed and filmed 104 tethered fish prey over 4 sampling days in the Ross Creek estuary in Townsville, north-eastern Australia $\left(19^{\circ} 15.30 \mathrm{~S}\right.$, $146^{\circ} 49.10 \mathrm{E}$ ). Tethering devices comprised a weighted base (concrete paver, $20 \mathrm{~cm} \times 20 \mathrm{~cm}, 4.2 \mathrm{~kg}$ ) with an underwater video camera (GoPro Hero $3+$ ), and an $18 \mathrm{~cm}$ long, $5 \mathrm{~mm}$ diameter semi-rigid plastic tether-arm extending into the field of view. An $18 \mathrm{~cm}$ tether line of $1 \mathrm{~kg}$ $(0.12 \mathrm{~mm}$ dia) monofilament fishing line was attached to the end of the tether arm, and fish were attached to the tether line via a size 14 finewire fish hook through the jaw. The length of the tether arm and tether line represented a trade-off that maximised the area accessible to the tethered fish while ensuring it remained in the field of view and within the typical visibility limits at the study site.

The taxa tethered on each occasion was the most abundant common prey fish captured by cast-net from the study site on the day of each trial. Fish were held in a $60 \mathrm{~L}$ insulated holding tank with regular water exchange. Trials each day commenced immediately once sufficient numbers of a single prey taxon were captured. Only one taxon was used per day, and all individuals were of similar size within each trial. Fish tethered were Ambassis vachelli ( $n=75$, mean TL: $50 \mathrm{~mm} \pm 1.1$ (SE)), Leiognathus spp. ( $n=12,43 \pm 1.2 \mathrm{~mm})$, and Herklotsichthys castelnaui $(n=17 ; 78 \pm 2.2 \mathrm{~mm}$ ), all of which are commonly consumed by a wide range of predatory fishes in estuaries in the region (Baker and Sheaves, 2005). After attachment to the tether line, fish were placed into a bucket of water to ensure they were swimming strongly and were then deployed within 5 min.

Tethers were deployed at depths between 1 and $4 \mathrm{~m}$ across a variety of modified habitats within the urbanised part of the estuary, including mangrove edge, rock wall, floating pontoon, vertical pylon, and unstructured open bottom $>20 \mathrm{~m}$ from structures listed above. Tethers were placed at least $20 \mathrm{~m}$ apart to ensure independence, and left undisturbed for at least $15 \mathrm{~min}$, providing replicate 15 -min trials. Trial duration was selected as a trade-off between longer trials that provide higher levels of prey loss, and shorter trials that minimize the duration that mobile prey were restrained on tethers and maximizing replication during suitable visibility conditions. All trials were conducted in daylight hours (1300-1730) during neap tidal phases when smaller tidal ranges provided adequate water clarity for successful video capture.

To assess the nature of events leading to the loss of tethered prey, each video was reviewed from the time of deployment until retrieval or prey loss from the tether line. When the prey was lost from the tether the event was classified into one of three categories: escaped - prey detached from hook without interference from predator or scavenger, includes prey detaching due to entanglement with structure on deployment or retrieval; scavenged/opportunistic predation - prey removed from hook by species that typically does not consume free-swimming untethered fish prey, or by a predator removing a prey much larger than it normally consumes; legitimate predation - prey removed from hook by predator for which fish prey of the size and species tethered are a normal part of the diet. Distinctions between opportunistic and legitimate predation for piscivorous species were based on published diet data and the relative sizes of predator and prey involved compared to typical predator prey size relationships (Baker and Sheaves, 2005). All events classified as opportunistic predation involved extensive manipulation of the prey by the predator, allowing ample opportunity to estimate their relative sizes. 


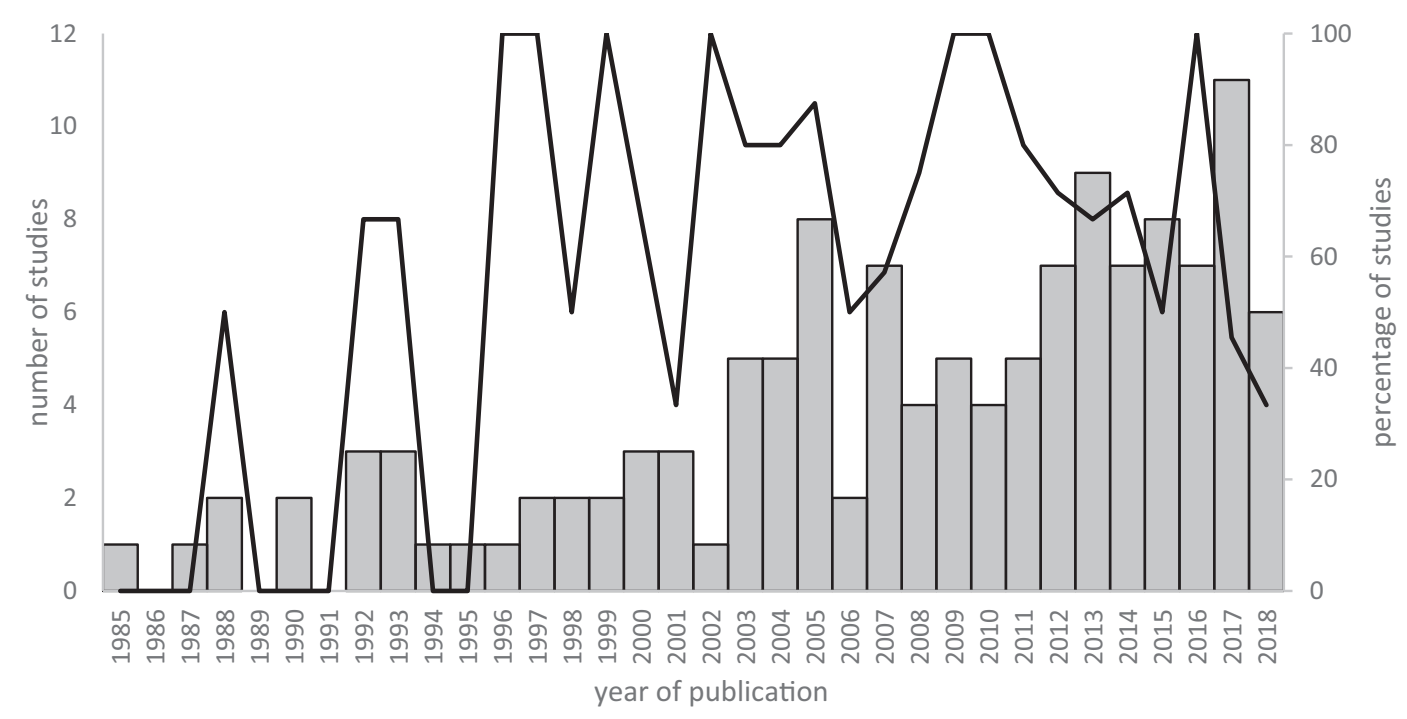

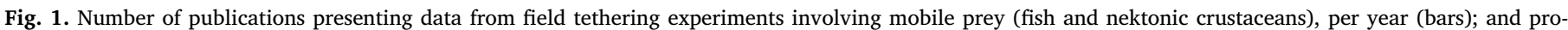
portion of studies acknowledging potential artefacts or biases that may confound results (line).

\section{Results}

\subsection{Literature review}

Our literature search produced 128 studies providing data on field tethering experiments of mobile nekton (see Supplement S1 for full list of references). The number of publications per year is increasing, particularly since the early 2000's, however the proportion that provide any discussion of potential biases or artefacts appears to be declining over the same time frame (Fig. 1). For example, only 7 of the 17 studies reporting results from tethering mobile prey in 2017-18 discussed potential issues with the technique. Eighty-five percent of studies $(n=109)$ considered prey missing from the tether line to represent predation (Table 1). The remaining 19 studies either observed $(n=2)$ or remotely recorded each predation event $(n=6)$, did not clarify what was considered to represent a predation event $(n=8)$, or distinguished what they considered to be legitimate predation from excluded results based on the condition of the tether line and the presence of partial prey remains $(n=3)$.

Sixteen percent of studies $(n=21)$ stated that they measured "predation rate" or some equivalent metric and interpreted results as if they provided an absolute measure of natural predation, with no mention of

\section{Table 1}

Summary of experimental characteristics of 128 publications presenting data from field tethering experiments involving mobile prey (fish and nektonic crustaceans). $\mathrm{N}=$ number of studies, $\%$ is percent of total, or when in parenthesis, percent of the 93 studies that provided information on the distance between replicate field deployments.

\begin{tabular}{lll}
\hline Characteristic & $\mathrm{N}$ & $\%$ \\
\hline Missing = predation & 109 & 85 \\
Absolute measure & 21 & 16 \\
Escape testing & 77 & 60 \\
Artefacts tested & 53 & 41 \\
Artefacts unacknowledged & 43 & 34 \\
All filmed/observed & 8 & 6 \\
Min dist. between replicates (m) & & \\
$\leq 1$ & 24 & $(26)$ \\
$>1-5$ & 39 & $(42)$ \\
$>5-10$ & 12 & $(13)$ \\
$>10-20$ & 8 & $(9)$ \\
$>20$ & 10 & $(11)$ \\
Not stated & 35 & 27 \\
Total studies & 128 & \\
\hline
\end{tabular}

any potential artefacts or biases of the method (Table 1). The remaining studies indicated they measured relative predation rate or some other relative measure, thereby acknowledging that predation rates on tethered prey do not necessarily reflect natural rates of predation on untethered prey (Aronson and Heck, 1995), even though many of these made no other mention of any potential biases. In almost all cases, regardless of the terminology used, results were based on patterns of prey loss from tethers and interpreted as reflecting patterns of predation, i.e. predation by predators that typically consume non-tethered prey, rather than some index of consumption or other conservative interpretation that would accommodate significant contributions by scavengers or opportunists.

Seventy-seven studies (60\%) performed some form of escape testing to assess the loss of tethered prey in the absence of predators (Table 1), including 23 studies that otherwise made no mention of potential biases with the tethering technique. For issues other than prey escape, $34 \%$ of all studies $(n=43)$ made no mention of any potential biases or artefacts, while the remaining $66 \%(n=85)$ explicitly acknowledged the possibility of issues (Table 1$)$. Less than half of all studies $(41 \%, n=53)$ reported or referenced any testing for potential biases or artefacts. Assessments included mesocosm or field observational studies of changes in behaviour or interactions between tethered prey and habitats. A few studies included direct comparisons of predation rates on tethered and untethered prey in laboratory conditions, to test for interactions between treatments and the effect of tethers on prey vulnerability to predation. All predation events were filmed or otherwise observed in 8 studies (6\%), allowing researchers to identify and distinguish what was considered to be legitimate predation events from biases or artefacts of the technique (Table 1). In all other cases, potential artefacts were dismissed, or the results of any testing were necessarily extrapolated when interpreting the findings of the study.

Twenty-seven percent of studies $(n=35)$ provided no information on the distance between tethered animals (Table 1). Of the 93 studies that provided this information, tethered individuals were deployed with minimum spacing of $1 \mathrm{~m}$ or less in $26 \%(n=24)$, and a further $42 \%$ $(n=39)$ deployed replicates no $>5 \mathrm{~m}$ apart. $<20 \%$ of studies $(n=18)$ deployed tethered individuals at least $10 \mathrm{~m}$ apart in the field (Table 1).

\subsection{Field tethering trials}

Thirty-one of the 104 tethering replicates had missing prey at the 


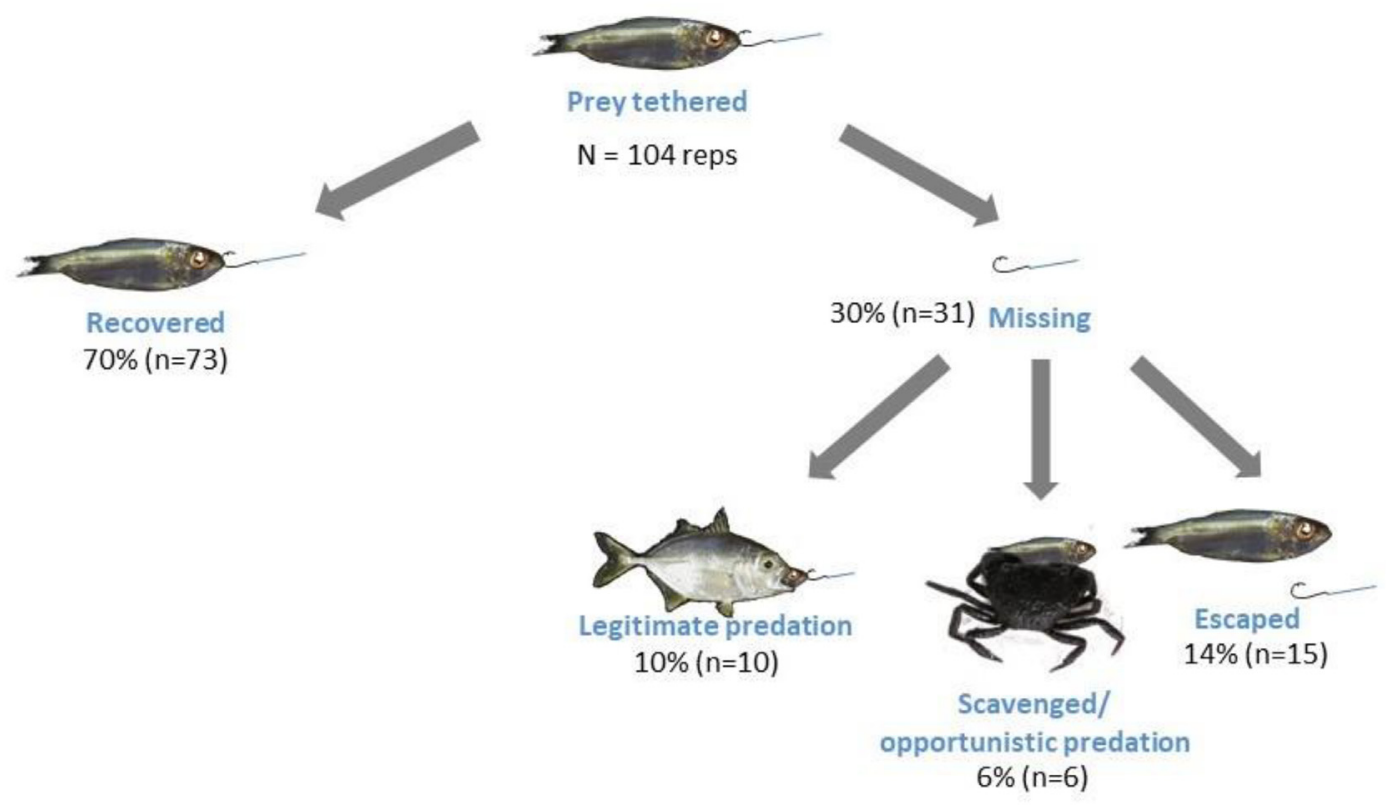

Fig. 2. The fate of tethered fish prey $(n=104)$ filmed with underwater video cameras during deployment in a tropical estuary.
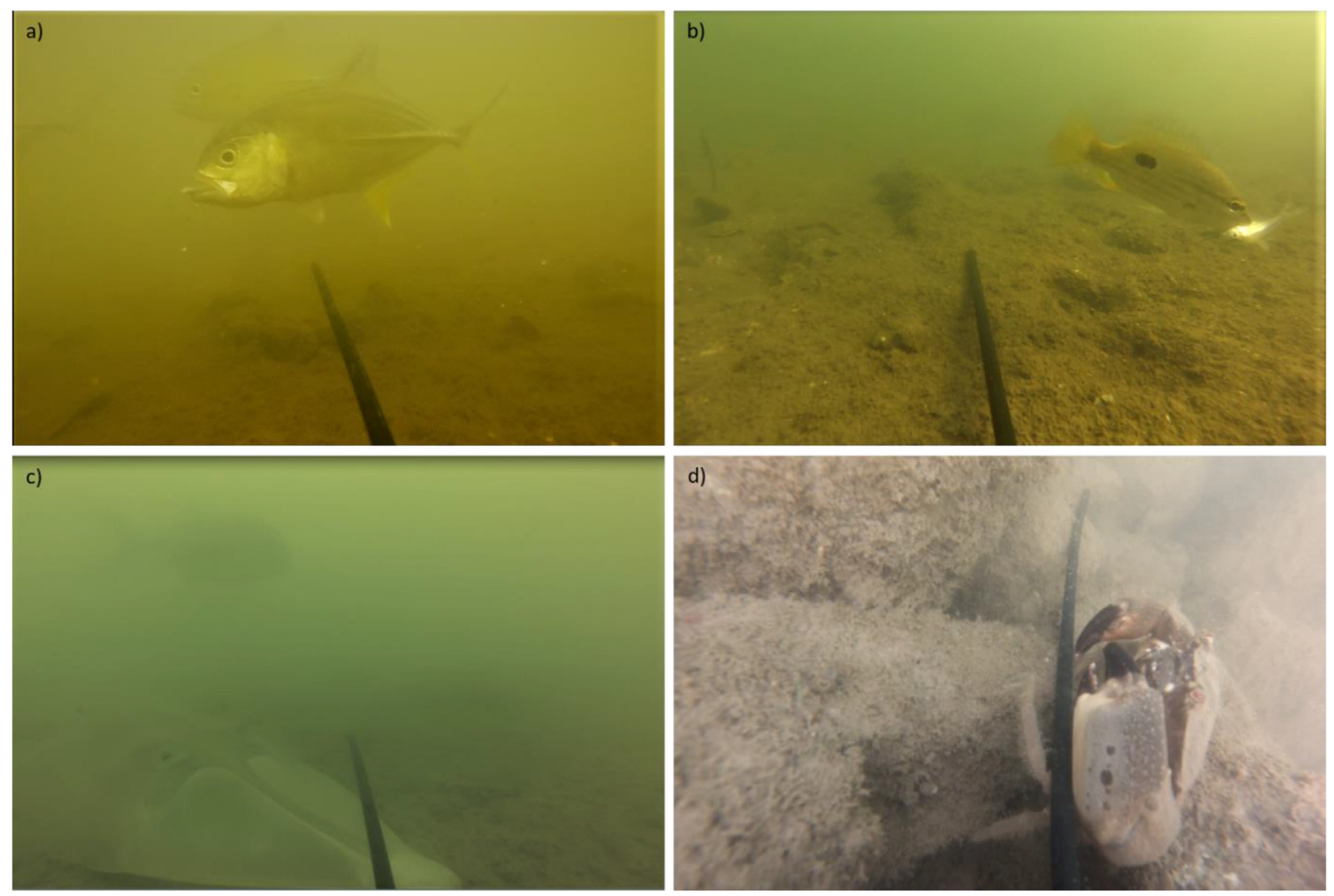

Fig. 3. Representative images of the removal of fish prey from tethers during filmed field trials. a) Caranx sp. considered a legitimate predator of the tethered fish prey; b) Lutjanus fulviflamma removing tethered Ambassis vachelli approximately $50 \%$ of predator length, classified as opportunistic predation since fish prey of this size are not a normal part of the diet; c) Shovelnose ray (Rhinobatidae) considered an opportunist since typical diet comprises crustaceans and molluscs (note Caranx sp. in background); d) Xanthid crab classified as scavenger.

end of the trial (Fig. 2). One third of these $(n=10)$ were classified as representing legitimate predation events (Fig. 2), i.e. removed by predators that would ordinarily consume prey of the size and type tethered (Fig. 3a). The rest either escaped $(n=15)$ or were removed by opportunistic predators or scavengers ( $n=6$; Figs. 2, 3b-d). If escaped prey are disregarded, more than one third of the missing prey were removed by scavengers or opportunists. Two of the prey classified as escaped were dislodged from the tether line through entanglement on structure during deployment or retrieval (e.g. the tether line was caught around a mangrove root), rather than simply escaping directly from the hook, and one escaped after repeated attacks by opportunistic predators (gape-limited gobiids around twice the length of the tethered prey). The 
initial trial ( $n=5$ replicates) placed the hook through the membrane behind the lower jaw, while subsequent trials placed the hook through the upper jaw to reduce escape of tethered fish.

\section{Discussion}

\subsection{Potential issues of tethering}

The potential challenges with tethering were identified and well discussed in the literature 20-25 years ago (Peterson and Black, 1994; Aronson and Heck, 1995; Aronson et al., 2001). Since that time the number of studies tethering mobile prey is increasing, yet so too is the proportion that do not explicitly consider the potential biases or artefacts that may confound interpretations. Of particular note, one third of all studies reviewed do not acknowledge the potential for artefacts associated with the methodology to bias or confound findings, and less than half of the studies either performed or referenced efforts to test for artefacts. Some carefully designed mesocosm and field studies convincingly demonstrate a lack of artefacts impacting their field tethering results (e.g. Dahlgren and Eggleston, 2000; Bromilow and Lipcius, 2017; Yeager and Hovel, 2017), yet a significant number of other studies have identified interactions between tethering and treatments that would invalidate the interpretation of field data (e.g. Haywood et al., 2003; Adams et al., 2004; Mills et al., 2008). From these studies, no consistent patterns emerge to suggest when tethering artefacts are more likely to be a problem, highlighting the importance of carefully considering potential issues when designing these experiments. While the potential biases and artefacts associated with tethering mobile prey are generally well known, a considerable number of recent studies appear to give little consideration of the potential implications for the data they present.

Our filmed field trials reiterate the simple point that prey missing from a tether at the end of a trial may be missing for a variety of reasons other than predation, which $85 \%$ of studies reviewed assumed missing prey to represent. Although tethers were deployed across a variety of habitats, the objectives of this preliminary field study were to determine the reason of prey loss, and to test the utility of filming tethering trials in relatively turbid estuarine waters. Our design, use of multiple prey species, and level of replication is inadequate to allow quantitative comparisons of predation among habitats, or to test for species-specific interactions between any tethering biases and habitat. While some studies convincingly demonstrate a lack of artefacts, many others identify serious problems that confound observed patterns. Whatever the quantitative findings of a more detailed study in our system may show, they would be specific to the conditions and prey types tethered at the time, and would not change the broader issue that without careful testing for artefacts and interactions with treatments, the patterns of loss of field tethered prey in any individual study may not reflect patterns of predation that we seek to understand.

Other authors have noted the value of direct observations for assessing potential artefacts in field tethering trials (e.g. Adams et al., 2004; Smith et al., 2011). The use of remote recording of trials remains uncommon, but the few studies that have employed it were able to distinguish between legitimate predation and scavenging or other causes of tethered prey loss, as well as examine the behaviour of tethered prey in situ during trials, and assess potential interactions between tethering and treatments that may confound results (Bassett et al., 2008; Smith et al., 2011; Frid et al., 2012; Bessey and Heithaus, 2013; Hesse et al., 2015; Lawrence et al., 2017). The underwater video approach we employed is suitable only for daylight hours and waters of sufficient visibility, yet it proved practical in a meso-tidal turbid estuary where horizontal visibility rarely exceeded $0.5 \mathrm{~m}$. Our findings emphasise the value of remote video for overcoming many of the potential confounding factors associated with tethering.

Almost half our missing prey were classified as escaped. Sixty percent of published tethering studies employ some form of escape testing to develop appropriate attachment methods that minimize the influence of prey escape on their findings (e.g. Halpin, 2000; Camp et al., 2012), or allow the distinction between escaped and removed prey missing from tethers (e.g. Chacin and Stallings, 2016; Yeager and Hovel, 2017). For example, Chacin and Stallings (2016) tethered pinfish using a loop of fine monofilament through the mouth and operculum such that a fish missing from an intact loop must have been forcibly removed rather than escaping. In our field trials, video provided an escape test for every replicate and allowed us to improve the prey attachment technique. The apparent lack of escape testing in $40 \%$ of published studies highlights the risk of inflated predation measures. Some form of escape testing should be incorporated into all tethering studies.

When we exclude all escaped prey from consideration, more than one third of the prey lost were removed by scavengers or opportunists. Our classification of predation events as either opportunistic or legitimate was based on the identity and relative sizes of predator and prey together with published species diets and predator-prey size relationships (Baker and Sheaves, 2005). There is a degree of subjectivity in these classifications, for example the consumption of a tethered prey that is fractionally larger than the predator would normally consume (e.g. Fig. 3b), or by predators with poorly understood diets. However, a benefit of filmed tethering trials is the opportunity to carefully consider the relevance of each individual prey loss event, and to potentially reclassify them as new data comes to light, rather than the default assumption that all prey loss is legitimate, or that the proportion of prey lost to other causes is consistent among treatments. Despite the possible subjectivity in some individual classifications, our data serves to reinforce the point that a potentially significant proportion of prey missing from tethers could be removed by animals that do not normally consume free-swimming prey of the type tethered (Adams et al., 2004; Haywood et al., 2003).

The potential for a lack of independence between replicate tethered prey was also apparent from the literature review. In a tethering study, independent replicates are those where the probability of a tethered prey being consumed is independent of the probability of adjacent tethered prey being consumed. If replicate mobile prey are deployed close enough that a predator consuming one prey can detect and be attracted to the next nearest tethered prey, then these replicates are not independent, and the patterns of recorded prey loss may be misleading (Gregory and Levings, 1998). Over one quarter of all studies tethering mobile fish and crustacean prey deployed what they treated as independent replicates at spacings of $1 \mathrm{~m}$ or less in the field, and a further $42 \%$ no more than $5 \mathrm{~m}$ apart. The appropriate spacing between replicates to ensure independence will vary among studies and systems. Factors such as the mobility, activity, and predator avoidance behaviour of tethered prey (e.g. actively swimming fish Vs cryptic crab), the structural complexity of the habitats in which prey are tethered (e.g. complex rocky reef vs bare sand), the hunting modes of the potential predators (e.g. visual, tactile, chemosensory), and environmental variables (e.g. water clarity, current speed) may all influence prey detection range and should be carefully considered when designing tethering experiments to ensure independence of individual replicates.

\subsection{Alternatives and solutions}

Many studies undertake some form of escape testing to demonstrate confidence that missing prey have not simply escaped from the tether (e.g. Dahlgren and Eggleston, 2000; Halpin, 2000; Camp et al., 2012; Chacin and Stallings, 2016). Such testing can provide a high level of confidence that escape contributes minimally to the loss of tethered prey, however the ultimate fate of unmonitored prey lost from tethers remains unknown. In our field trials, video footage provided a means of escape testing for every replicate deployed, and identified the need to modify our attachment method. Despite this, some escaped after unsuccessful attacks by opportunists, and others were dislodged through entanglement on structure during deployment or retrieval. The loss of 
tethered prey through entanglement seems likely to interact with the physical structure of habitat, and could therefore confound amonghabitat comparisons (Minello, 1993; Peterson and Black, 1994; Adams et al., 2004). While it may be possible to enter the water to deploy and recover tethers thereby ensuring entanglement does not contribute to recorded prey loss, in many situations this will not be practical. We encourage escape testing, using video or other means, for all tethering experiments.

The underwater video approach used here offers several additional benefits. It provides information on the identity of consumers that remove or interact with tethered prey, allows monitoring of prey behaviour throughout trials, and may identify interactions between tethering artefacts and the treatment being tested (Smith et al., 2011). It also provides data on the composition of the fish/nekton assemblage present in the habitats being sampled (e.g. Dunbar et al., 2017), and such data can greatly enhance interpretation and understanding of the processes shaping these communities (Bradley et al., 2019). Complementary data on community composition is usually collected through a variety of sampling approaches such as netting (e.g. Linehan et al., 2001; Manderson et al., 2006) or visual census (e.g. Nanjo et al., 2014), each with their own limitations which may not well represent the community in the habitats being sampled for predation (Rozas and Minello, 1997). Filmed tethering trials provide data on the community composition in the precise location and time of each tethering replicate, potentially providing more relevant data (Smith et al., 2011), and simplifying the logistics of field sampling. Video also provides data on the habitat sampled that may not be apparent during deployment (Bradley et al., 2017) but may influence predation processes.

The use of underwater video has its own limitations and will not be suitable for all applications of field tethering trials. Examining patterns of predation at night (e.g. Peterson et al., 2001) or in highly turbid waters (e.g. Gregory and Levings, 1998) is not currently possible with standard video, and the addition of artificial light may introduce other confounding factors (Becker et al., 2013). Many aquatic systems where tethering studies occur are characterised by moderately turbid waters, at least some of the time. While video has been successfully employed in these systems, it is typically limited to periods favouring clearer water such as minimal tidal range, or seasons with low rainfall (e.g. this study, Bradley et al., 2017, Dunbar et al., 2017). These limitations make it challenging to use video tethering to assess tidal (Manderson et al., 2004), diel (Peterson et al., 2001), lunar (Acosta and Butler, 1999) and seasonal (Camp et al., 2012) drivers of predation pressure in systems with marginal turbidity or visibility. Additionally, although the cost of underwater video units is declining, the cost of cameras is still orders of magnitude greater than the rest of the materials required for field tethering experiments, and may prove prohibitive for some situations. If so, then filming at least a subset of field tethering trials can still help clarify interpretation of these experiments (e.g. Mills et al., 2008).

Carefully designed mesocosm and field tests for tethering artefacts will continue to be important in addition to video, or in situations when video is not viable. Mesocosm studies testing for interactions between tethering and treatments such as habitat complexity can be useful in systems with a relatively low diversity of potential predators (e.g. Mills et al., 2008; Yeager and Hovel, 2017). In systems with a high diversity of predatory taxa spanning a wide size range and that employ various modes of predation (e.g. Baker and Sheaves, 2007), developing appropriate mesocosm tests for artefacts is much more challenging. For example, in tropical estuaries where the assemblage of potential predators may range from small cryptic benthic ambush predators to large and highly mobile species (e.g. Baker and Sheaves, 2005), the mesocosm facilities required for tests involving even a limited range of potential predator taxa would be impractical for most researchers. Despite the challenges, testing for artefacts that may confound results should be high priority for future applications of tethering mobile prey.

\section{Conclusions}

The concerns raised here should not be taken to imply that all previous studies tethering mobile prey are flawed. Indeed, several studies carefully assess potential artefacts using underwater video (e.g. Smith et al., 2011; Bessey and Heithaus, 2013) or laboratory and field tests (e.g. Dahlgren and Eggleston, 2000; Yeager and Hovel, 2017) that give confidence in the data presented, while others have identified serious artefacts that confound results. Clearly, some of the published studies that do not explicitly discuss potential artefacts would still contain robust estimates of real patterns in predation, while others have likely made conclusions based on evidence drawn from confounded tethering results. The key issue is that without careful consideration and testing in each case, the validity of tethering data remains unknown.

We support the continued application of carefully designed tethering experiments (e.g. Dahlgren and Eggleston, 2000; Linehan et al., 2001; Chacin and Stallings, 2016; Lawrence et al., 2017; Riley and Griffin, 2017), particularly as part of larger studies combining multiple lines of evidence to explain observed patterns (e.g. Wahle and Steneck, 1992; Halpin, 2000; Aronson et al., 2001; Manderson et al., 2006; Riley and Griffin, 2017), and where careful testing is conducted to assess the potential for confounding artefacts (e.g. Mills et al., 2008; Smith et al., 2011; Yeager and Hovel, 2017). These experiments remain one of the few options for examining patterns of predation in aquatic ecosystems, but our literature review revealed that the well described problems with the technique are increasingly glossed over by many authors. We reiterate earlier calls for caution when applying this technique (Peterson and Black, 1994; Aronson et al., 2001; Mills et al., 2008; Smith et al., 2011), and advocate for rigorous testing of potential artefacts using underwater video or carefully designed laboratory and field experiments to ensure robust interpretations from reliable data.

\section{Funding}

This research did not receive any specific grant from funding agencies in the public, commercial, or not-for-profit sectors.

\section{Declaration of Competing Interest}

None.

\section{Acknowledgments}

Both authors conceived and designed the study, and conducted the field trials. NW analysed the video footage of field trials. RB conducted and analysed the literature review, and wrote the paper with input from NW. This work was conducted under Qld General Fisheries Permit 114026, and in accordance with ethical requirements for animal based research under JCU Ethics Permit A1931.

\section{Appendix A. Supplementary data}

Supplementary data to this article can be found online at https:// doi.org/10.1016/j.jembe.2019.151270.

\section{References}

Acosta, C.A., Butler, M.J., 1999. Adaptive strategies that reduce predation on Caribbean spiny lobster postlarvae during onshore transport. Limnol. Oceanogr. 44, 494-501.

Adams, A.J., Miller, R., Ebersole, J.P., 2004. Tethers make juvenile surgeonfish (Acanthuridae) vulnerable to attacks by benthic invertebrates. Bull. Mar. Sci. 74, 207-211.

Aronson, R.B., 1988. Palatability of five Caribbean ophiuroids. Bull. Mar. Sci. 43, 93-97. Aronson, R.B., 1989. Brittlestar beds: low-predation anachronisms in the British Isles. Ecology 70, 856-865.

Aronson, R.B., Heck, K.L., 1995. Tethering experiments and hypothesis testing in ecology. Mar. Ecol. Prog. Ser. 121, 307-309.

Aronson, R.B., Heck, K.L., Valentine, J.F., 2001. Measuring predation with tethering 
experiments. Mar. Ecol. Prog. Ser. 214, 311-312.

Baker, R., Sheaves, M., 2005. Redefining the piscivore assemblage of shallow estuarine nursery habitats. Mar. Ecol. Prog. Ser. 291, 197-213.

Baker, R., Sheaves, M., 2007. Shallow-water refuge paradigm: conflicting evidence from tethering experiments in a tropical estuary. Mar. Ecol. Prog. Ser. 349, 13-22.

Barshaw, D.E., Able, K.W., 1990. Tethering as a technique for assessing predation rates in different habitats: an evaluation using juvenile lobsters Homarus americanus. Fish. Bull. 88, 415-417.

Bassett, D.K., Jeffs, A.G., Montgomery, J.C., 2008. Identification of predators using a novel photographic tethering device. Mar. Freshw. Res. 59, 1079-1083.

Becker, A., Whitfield, A.K., Cowley, P.D., Jarnegren, J., Naesje, T.F., 2013. Potential effects of artificial light associated with anthropogenic infrastructure on the abundance and foraging behaviour of estuary-associated fishes. J. Appl. Ecol. 50, 43-50.

Bessey, C., Heithaus, M.R., 2013. Alarm call production and temporal variation in predator encounter rates for a facultative teleost grazer in a relatively pristine seagrass ecosystem. J. Exp. Mar. Biol. Ecol. 449, 135-141.

Bradley, M., Baker, R., Sheaves, M., 2017. Hidden components in tropical seascapes: deep-estuary habitats support unique fish assemblages. Estuar Coast 40, 1195-1206.

Bradley, M., Baker, R., Nagelkerken, I., Sheaves, M., 2019. Context is more important than habitat type in determining use by juvenile fish. Landsc. Ecol. 34, 427-442.

Bromilow, A.M., Lipcius, R.N., 2017. Mechanisms governing ontogenetic habitat shifts: role of trade-offs, predation, and cannibalism for the blue crab. Mar. Ecol. Prog. Ser. 584, 145-159.

Camp, E.V., Gwinn, D.C., Pine, W.E., Frazer, T.K., 2012. Changes in submersed aquatic vegetation affect predation risk of a common prey fish Lucania parva (Cyprinodontiformes: Fundulidae) in a spring-fed coastal river. Fish. Manag. Ecol. 19, 245-251.

Chacin, D.H., Stallings, C.D., 2016. Disentangling fine-and broad-scale effects of habitat on predator-prey interactions. J. Exp. Mar. Biol. Ecol. 483, 10-19.

Curran, M.C., Able, K.W., 1998. The value of tethering fishes (winter flounder and tautog) as a tool for assessing predation rates. Mar. Ecol. Prog. Ser. 163, 45-51.

Dahlgren, C.P., Eggleston, D.B., 2000. Ecological processes underlying ontogenetic habitat shifts in a coral reef fish. Ecology 81, 2227-2240.

Dunbar, K., Baker, R., Sheaves, M., 2017. Effects of forest width on fish use of fringing mangroves in a highly urbanised tropical estuary. Mar. Freshw. Res. 68, 1764-1770.

Frid, A., Marliave, J., Heithaus, M.R., 2012. Interspecific variation in life history relates to antipredator decisions by marine mesopredators on temperate reefs. PLoS One 7 (6), e40083.

Gregory, R.S., Levings, C.D., 1998. Turbidity reduces predation on migrating juvenile Pacific salmon. Trans. Am. Fish. Soc. 127, 275-285.

Halpin, P.M., 2000. Habitat use by an intertidal salt-marsh fish: trade-offs between predation and growth. Mar. Ecol. Prog. Ser. 198, 203-214.

Haywood, M.D., Manson, F.J., Loneragan, N.R., Toscas, P.J., 2003. Investigation of artifacts from chronographic tethering experiments - interactions between tethers and predators. J. Exp. Mar. Biol. Ecol. 290, 271-292.

Hesse, J., Stanley, J.A., Jeffs, A.G., 2015. Do changes in reef habitats influence relative predation risk on the juvenile Australasian spiny lobster, Jasus edwardsii (Hutton, 1875)? Crustaceana 88, 839-856.
Kneib, R.T., Scheele, C.H., 2000. Does tethering of mobile prey measure relative predation potential? An empirical test using mummichogs and grass shrimp. Mar. Ecol. Prog. Ser. 198, 181-190.

Lawrence, M.J., Eliason, E.J., Brownscombe, J.W., Gilmour, K.M., Mandelman, J.W., Cooke, S.J., 2017. An experimental evaluation of the role of the stress axis in mediating predator-prey interactions in wild marine fish. Comp Biochem Physiol A Mol Integr Physiol 207, 21-29.

Linehan, J.E., Gregory, R.S., Schneider, D.C., 2001. Predation risk of age-0 cod (Gadus) relative to depth and substrate in coastal waters. J. Exp. Mar. Biol. Ecol. 263, 25-44.

Manderson, J.P., Pessutti, J., Hilbert, J.G., Juanes, F., 2004. Shallow water predation risk for a juvenile flatfish (winter flounder; Pseudopleuronectes americanus, Walbaum) in a northwest Atlantic estuary. J. Exp. Mar. Biol. Ecol. 304, 137-157.

Manderson, J.P., Pessutti, J., Shaheen, P., Juanes, F., 2006. Dynamics of early juvenile winter flounder predation risk on a North West Atlantic estuarine nursery ground. Mar. Ecol. Prog. Ser. 328, 249-265.

Mills, D.J., Johnson, C.R., Gardner, C., 2008. Bias in lobster tethering experiments conducted for selecting low-predation release sites. Mar. Ecol. Prog. Ser. 364, 1-13.

Minello, T.J., 1993. Chronographic tethering: a technique for measuring prey survival time and testing predation pressure in aquatic habitats. Mar. Ecol. Prog. Ser. 101, 99-104.

Nanjo, K., Kohno, H., Nakamura, Y., Horinouchi, M., Sano, M., 2014. Effects of mangrove structure on fish distribution patterns and predation risks. J. Exp. Mar. Biol. Ecol. 461, 216-225.

Peterson, C.H., Black, R., 1994. An experimentalist's challenge: when artifacts of intervention interact with treatments. Mar. Ecol. Prog. Ser. 111, 289-297.

Peterson, B.J., Thompson, K.R., Cowan, J.H., Heck, K.L., 2001. Comparison of predation pressure in temperate and subtropical seagrass habitats based on chronographic tethering. Mar. Ecol. Prog. Ser. 224, 77-85.

Pursche, A.R., Suthers, I.M., Taylor, M.D., 2009. Tethering induces increased stress artifacts in social fish species. J. Fish Biol. 74, 1525-1531.

Riley, M.E., Griffin, B.D., 2017. Habitat-specific differences alter traditional biogeographic patterns of life history in a climate-change induced range expansion. PLoS One 12 (5), e0176263.

Rozas, L.P., Minello, T.J., 1997. Estimating densities of small fishes and decapod crustaceans in shallow estuarine habitats: a review of sampling design with focus on gear selection. Estuaries 20, 199-213.

Smith, T.M., Hindell, J.S., Jenkins, G.P., Connolly, R.M., Keough, M.J., 2011. Edge effects in patchy seagrass landscapes: the role of predation in determining fish distribution. J. Exp. Mar. Biol. Ecol. 399, 8-16.

Wahle, R.A., Steneck, R.S., 1992. Habitat restrictions in early benthic life: experiments on habitat selection and in situ predation with the American lobster. J. Exp. Mar. Biol. Ecol. 157, 91-114.

Yeager, M.E., Hovel, K.A., 2017. Structural complexity and fish body size interactively affect habitat optimality. Oecologia 185, 257-267.

Zimmer-Faust, R.K., Fielder, D.R., Heck, K.L., Coen, L.D., Morgan, S.G., 1994. Effects of tethering on predatory escape by juvenile blue crabs. Mar. Ecol. Prog. Ser. 111, 299-303. 